\title{
Seasonality and Regionality of the Madden-Julian Oscillation, Kelvin Wave, and Equatorial Rossby Wave
}

\author{
Hirohiko MaSUnAGA* \\ Colorado State University, Fort Collins, Colorado
}

(Manuscript received 19 May 2006, in final form 27 March 2007)

\begin{abstract}
The Madden-Julian oscillation (MJO), Kelvin wave, and equatorial Rossby (ER) wave-collectively called intraseasonal oscillations (ISOs) - are investigated using a 25-yr record of outgoing longwave radiation (OLR) measurements as well as the associated dynamical fields. The ISO modes are detected by applying bandpass filters to the OLR data in the frequency-wavenumber space. An automated wavetracking algorithm is applied to each ISO mode so that convection centers accompanied with the ISOs are traced in space and time in an objective fashion. The identified paths of the individual ISO modes are first examined and found strongly modulated regionally and seasonally. The dynamical structure is composited with respect to the convection centers of each ISO mode. A baroclinic mode of the combined Rossby and Kelvin structure is prominent for the MJO, consistent with existing work. The Kelvin wave exhibits a low-level wind field resembling the shallow-water solution, while a slight lead of low-level convergence over convection suggests the impact of frictional boundary layer convergence on Kelvin wave dynamics. A lagged composite analysis reveals that the MJO is accompanied with a Kelvin wave approaching from the west preceding the MJO convective maximum in austral summer. MJO activity then peaks as the Kelvin and ER waves constructively interfere to enhance off-equatorial boundary layer convergence. The MJO leaves a Kelvin wave emanating to the east once the peak phase is passed. The approaching Kelvin wave prior to the development of MJO convection is absent in boreal summer and fall. The composite ER wave, loosely concentrated around the MJO, is nearly stationary throughout. A possible scenario to physically translate the observed result is also discussed.
\end{abstract}

\section{Introduction}

The tropical 40-50-day oscillation originally discovered by Madden and Julian (1971), generally called the Madden-Julian oscillation (MJO), has spawned numerous studies in efforts to understand its physical nature. The MJO is an eastward-propagating, equatorially trapped mode with its vertical structure being dominantly baroclinic (Madden and Julian 1972). These fundamental features are at first glance reminiscent of the convectively coupled Kelvin wave, but MJO propagation is considerably slower and more dispersive than

\footnotetext{
* Current affiliation: Hydrospheric Atmospheric Research Center, Nagoya University, Nagoya, Japan.
}

Corresponding author address: Hirohiko Masunaga, Hydrospheric Atmospheric Research Center, Nagoya University, Furocho, Chikusa-ku, Nagoya 464-8601, Japan.

E-mail: masunaga@hyarc.nagoya-u.ac.jp expected for the moist Kelvin wave. Whereas a zonal wind anomaly is predominant near the equator, a cyclonic (anticyclonic) horizontal circulation in the lower (upper) troposphere off the equator is typically observed in association with the MJO. Many authors discussed this combined Rossby and Kelvin structure in terms of the atmospheric response to a local heat anomaly induced by MJO convection (see review by Zhang 2005 and references therein).

The Rossby and Kelvin waves accompanied with the MJO are not necessarily only a passive response to convective heating. Masunaga et al. (2006) pointed out the potential roles of the Kelvin and equatorial Rossby (ER) waves in the MJO propagation mechanism. Satellite precipitation data analyzed by Masunaga et al. (2006) showed that the MJO envelope occasionally encompasses a group of Kelvin waves as well as incoming ER waves that often interrupt Kelvin wave propagation. Their result suggests the possibility that neighboring ridges of the interrupted Kelvin wave as a whole could account for the slow eastward propagation of the 
MJO. The analysis of Masunaga et al. (2006), however, is limited to subjective diagnosis based on $10 \mathrm{MJO}$ episodes. In this work, long-term outgoing longwave radiation (OLR) data are analyzed to seek climatological evidence (or its absence) of the Kelvin and ER waves as a driver of MJO propagation.

Seasonality and regionality of the MJO, which were outside the scope of Masunaga et al. (2006), are also a major interest of the present study. Although the MJO is a planetary-scale, year-round phenomenon, notable regional and seasonal variability is generally well recognized. MJO activity normally peaks spatially over the west Pacific warm pool through the South Pacific convergence zone (SPCZ; e.g., Salby and Hendon 1994; Matthews et al. 1996; Yanai et al. 2000) and seasonally in austral summer (Madden 1986; Gutzler and Madden 1989; Zhang and Dong 2004). The boreal summer MJO tends to migrate northward from the Indian Ocean (e.g., Yasunari 1979; Lau and Chan 1986; Lawrence and Webster 2002). The seasonality and regionality of the MJO imply that the amplitude and propagation direction of the MJO are susceptible to strong modulations by geophysical conditions such as sea surface temperature (SST) and geographical constraint. Such environmental factors, in addition to atmospheric disturbances brought by large-scale waves, likely provide a crucial physical element that drives the MJO.

The present study analyzes the MJO, Kelvin wave, and ER wave, which are collectively called the intraseasonal oscillation (ISO) modes for convenience in this paper. A $25-\mathrm{yr}$ record of satellite-measured OLR is bandpass filtered in the frequency-wavenumber space to extract each ISO mode. Since OLR is a proxy of deep convection, OLR-filtered waves are considered to represent convectively coupled modes. The Kelvin (ER) wave is therefore meant to be the "moist" Kelvin (ER) wave throughout this paper unless otherwise indicated. The dynamical field associated with each ISO mode and a possible relationship of the MJO with the Kelvin and ER waves are explored by a compositing technique with an automated wave-tracking algorithm.

Data and analysis methods adopted in this study are described in section 2, followed by section 3 where the analyzed results are presented. The current findings are then discussed and summarized in the context of a possible scenario proposed to interpret the results (section 4).

\section{Data and method}

The daily, $2.5^{\circ} \times 2.5^{\circ}$ global OLR dataset provided by National Oceanic and Atmospheric Administration (NOAA) is employed. The NOAA OLR is converted from polar-orbiting satellite measurements at infrared window channels through an analytic formula (Gruber and Krueger 1984). A 25-yr record from 1 January 1980 to 31 December 2004 is analyzed in the present paper. For investigating dynamical field associated with the ISOs, the daily datasets of horizontal winds and geopotential height are taken from the National Centers for Environmental Prediction-National Center for Atmospheric Research (NCEP-NCAR) reanalysis data (Kalnay et al. 1996).

Sinusoidal backgrounds with the periods of one, a half, and a quarter year are removed in advance from the OLR and dynamical fields in order to isolate intraseasonal variations from the contamination of seasonal cycle. It is noted that any seasonal dependence unaccountable by the first three harmonics of the annual cycle would be left behind in the datasets. This remnant component of seasonality in the ISO characteristics is a primary interest of this work. The December-February (DJF) months are denoted as austral summer, March-May (MAM) as austral fall, JuneAugust (JJA) as boreal summer, and SeptemberNovember (SON) as boreal fall, except for the spectral analysis where a 128-day sequence is assigned to each season as described later. El Niño periods are removed from any seasonal category in order to factor ENSOrelated anomaly out of climatological patterns, as also done by Wheeler and Hendon (2004). The standardized Southern Oscillation index (SOI) is used for identifying El Niño events (Trenberth 1984). El Niño is considered to have occurred for months when the standardized SOI, temporally smoothed by 5 -month moving average, is lower than -1 . In total, 60 months are identified as El Niño between the years of 1980 and 2004.

Frequency-wavenumber analysis of OLR is conducted using the scheme described by Masunaga et al. (2006), who modified the method originally proposed by Wheeler and Kiladis (1999), except for specific differences mentioned below. In the current analysis, the space-time spectrum is broken down by three latitudinal sections of $15^{\circ}-5^{\circ} \mathrm{S}, 5^{\circ} \mathrm{S}-5^{\circ} \mathrm{N}$, and $5^{\circ}-15^{\circ} \mathrm{N}$, and is then further separated by different seasons. Symmetric and antisymmetric decomposition (Yanai and $\mathrm{Mu}$ rakami 1970) is not performed so that the separated latitudinal bands are treated independently of each other. Each season is defined by a 128-day time sequence centered on 15 January, 16 April, 16 July, and 15 October for the spectral analysis. Each end of a time sequence overlaps with the adjacent sequence for the sake of minimizing the data loss by tapering. The statistical significance of spectral power is evaluated based on the Student's $t$ test against the red-noise spectrum from 125 (5 latitudes $\times 25 \mathrm{yr}$ ) spectral samples for each 
meridional band and each season. Since neighboring latitudinal slips may be somewhat correlated with each other, the degrees of freedom are chosen to be a conservative value of $50-1=49$ when the statistical significance is quantified. The explicit form of the rednoise spectrum $p_{\text {rn }}$ is given as (section 11.2.5 in von Storch and Zwiers 1999)

$$
p_{\mathrm{rn}}(k, \omega)=\frac{\sigma_{Z}^{2}(k)}{1+\alpha_{1}(k)^{2}-2 \alpha_{1}(k) \cos (2 \pi \omega)},
$$

where $k$ is zonal wavenumber, $\omega$ is frequency, $\sigma_{Z}^{2}$ is the variance of driving white noise, and $\alpha_{1}$ is lag- 1 autocorrelation coefficient computed from the observed time series whose longitudinal component is transformed into wavenumber space. In Eq. (1), $\sigma_{Z}^{2}$ is chosen so that it is equivalent to the amplitude of the original spectrum when integrated over frequency at each wavenumber. El Niño months are not isolated in the spectral analysis because otherwise a sufficient number of 128day time series would be difficult to sample.

The ISOs are tracked in space and time by the following procedure. Individual ISO modes are identified by applying bandpass filters to the time-longitude series of OLR at each latitude (every $2.5^{\circ}$ ) between $20^{\circ} \mathrm{S}$ and $20^{\circ} \mathrm{N}$. The filter design adopted in this paper, as also indicated in the space-time spectrum shown later (Fig. 2), is summarized as follows. The MJO filter is defined by a rectangular filter bound between 20 and 80 days in cycle and 1 and 7 in wavenumber. This period range includes a majority of the observed MJO periods (from 22 to 79 days) as documented by Madden and Julian (1994). An alternative MJO filter, slightly narrowed to 30-80 days, was also tried and found to make no statistically significant change in composite diagrams (not shown). The Kelvin wave filter is bounded by $1 \leq$ $k \leq 10,0.05 \leq \omega \leq 0.25$ cycles per day (cpd) (4-20 days in period), and a pair of theoretical dispersion relations with the equivalent depths of 5 and $100 \mathrm{~m}$. A smaller equivalent depth, or a lower phase speed, in general represents a convectively coupled mode. Large-scale waves are slowed down when coupled with the moist processes, which may be ascribable to a reduction in the effective static stability (Chang 1977; Emanuel et al. 1994; Neelin and Yu 1994) and/or to the selection of shallower vertical modes in response to particular heating profiles (Mapes 2000; Wheeler et al. 2000; see also review by Wheeler and Kiladis 1999). The $n=1$ ER wave filter is defined between $-10 \leq k<0$ and two dispersion relations with the equivalent depths of 5 and $100 \mathrm{~m}$.

The spatial maximum of convective activity associated with a given ISO mode is located first by the me-
TABLE 1. Number of the ISO convection centers identified for different seasons and regions.

\begin{tabular}{lccc}
\hline Season/region & MJO & Kelvin & ER \\
\hline Austral summer & 4962 & 5933 & 9170 \\
Austral fall & 4976 & 6675 & 9126 \\
Boreal summer & 3271 & 4937 & 7191 \\
Boreal fall & 4159 & 5040 & 8556 \\
Indian Ocean & 4365 & 4656 & 6109 \\
Pacific Ocean & 4230 & 6245 & 6974 \\
\hline
\end{tabular}

ridional minimum in the filtered OLR at each longitude. The meridional range to search is from $20^{\circ} \mathrm{S}$ to $20^{\circ} \mathrm{N}$ for the $\mathrm{MJO}$ and ER wave, while a narrower range of $12.5^{\circ} \mathrm{S}$ to $12.5^{\circ} \mathrm{N}$ is chosen for the Kelvin wave in order to avoid the contamination of extratropical Rossby wave (Straub and Kiladis 2003a; Roundy and Frank 2004a). The linear shallow-water theory (Matsuno 1966) predicts that the amplitude of the equatorial Kelvin wave decays poleward at the $e$-folding scale of $(2 \sqrt{g h} / \beta)^{1 / 2}$, where $g, \beta$, and $h$ are the gravitational acceleration, meridional derivative of the Coriolis parameter, and equivalent depth, respectively. This decaying scale varies from 970 to $1390 \mathrm{~km}$ for a plausible range of $h$ between 12 and $50 \mathrm{~m}$ (Wheeler and Kiladis 1999). The meridional coverage of $\pm 12.5^{\circ}$ or $\pm 1390 \mathrm{~km}$ is thus sufficient to detect a vast majority of real Kelvin wave signals.

Zonal local minima in the filtered OLR are then sought among a series of the meridional minima across longitudes. The local minima are defined within the search radius of $\pm 15^{\circ}$ in longitude, ignoring noisy fluctuations on smaller scales. This threshold has been chosen conservatively, given that the ISO filters in use exclude any spatial structures finer than a zonal wavenumber of 10 . This procedure to find zonal local minima is carried out in a way similar to moving averaging, allowing the successive $\pm 15^{\circ}$ slips to overlap. The identified OLR minima are considered to represent "ISO convection centers" when the amplitude exceeds twice the standard deviation of the filtered OLR for individual ISO modes. The standard deviations of the filtered OLR are 8.90, 9.29, and $9.37 \mathrm{~W} \mathrm{~m}^{-2}$ for the MJO, Kelvin wave, and ER wave, respectively. The total number of the ISO convection centers identified in this study is listed in Table 1 . The $2 \sigma$ criterion mentioned above, aimed at removing noisy components, might be thought to put excessive focus on extreme cases. This criterion is, however, unlikely to damage the representativeness of the selected ISO modes. The numbers listed Table 1 would increase only by a small factor $(\sim 1.5-3.5)$ if the $2 \sigma$ threshold were not applied. The procedure to select the spatial minima of OLR has 


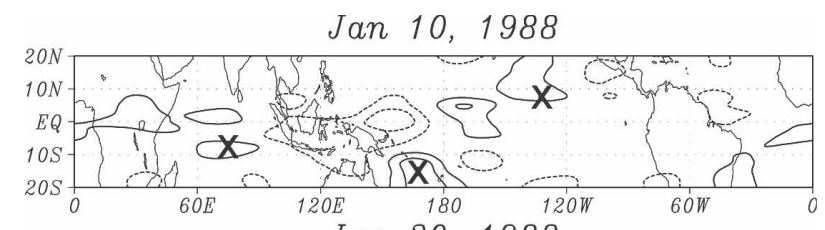

Jan 20, 1988

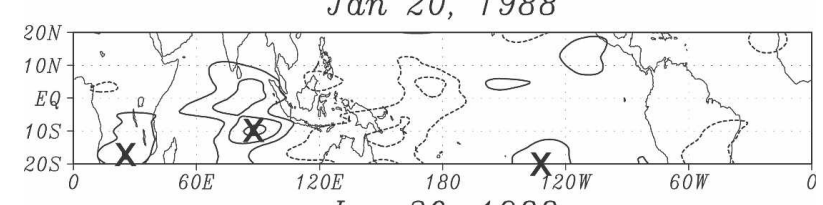

Jan 30, 1988

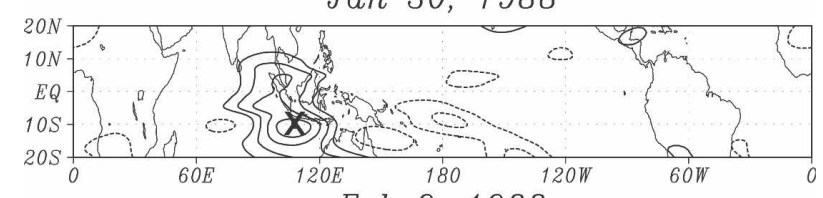

Feb 9, 1988

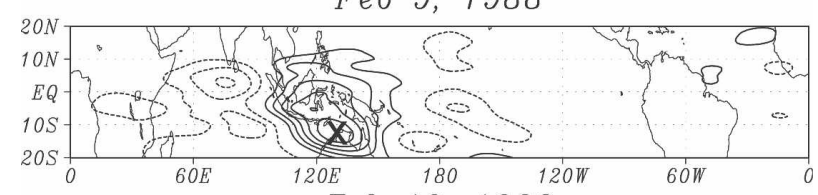

Feb 19, 1988

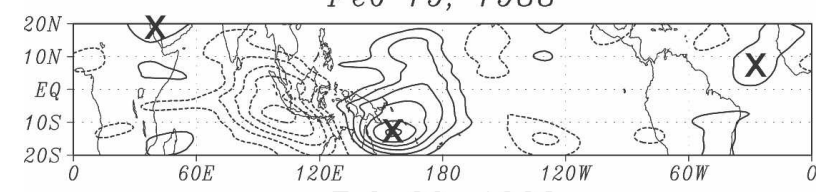

Feb 29, 1988

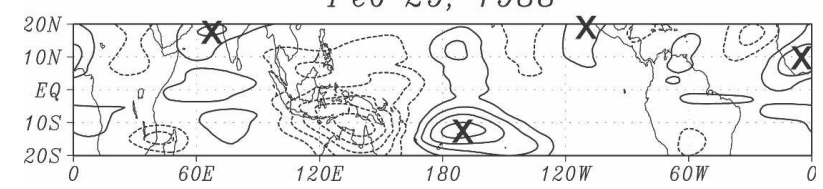

FIG. 1. A temporal sequence of MJO events is depicted every 10 days starting from 10 January 1988. MJO-filtered OLR is drawn at intervals of $10 \mathrm{~W} \mathrm{~m}^{-2}$ with solid (dashed) contour for negative (positive) anomalies, where zero contour is omitted. MJO convection centers identified by the tracking algorithm introduced in section 2 are marked by crosses.

already narrowed down the convection center candidates to some extent.

The performance of the ISO-tracking algorithm is delineated in the sequential maps of sample MJO episodes (Fig. 1). MJO-filtered OLR is depicted every 10 days together with MJO convection centers (marked by cross) identified in the manner described above. On the first day (10 January), three convection centers are observed in the Indian Ocean, SPCZ, and intertropical convergence zone (ITCZ). The first MJO event, initiated in the Indian Ocean, intensifies as it propagates to the east, while the other two events die out in the east Pacific. Convective activity associated with the first event eventually peaks in the SPCZ on 19 February, and starts decaying as it proceeds beyond the date line (29 February). Separate MJO events also appear in the
Atlantic Ocean and in the Red Sea through the Arabian Sea, moving eastward in the last two snapshots. A transient feature that appears over Africa on 20 January vanishes if the MJO filter is cut off at the period of 30 days instead of 20 days, while the major characteristics described above remain the same. Figure $1 \mathrm{dem}-$ onstrates that the ISO-tracking algorithm is overall successful in capturing the fundamental features of ISO propagation recorded in the OLR dataset.

A composite analysis is performed to examine the dynamical structure associated with each ISO mode. A composite diagram is constructed with respect to spatially variable base points given by the ISO convection centers defined above. A lagged composite analysis and a composite time-longitude analysis are also carried out to explore possible relationships among different ISO modes, where filtered OLR variance for the Kelvin and ER waves is composited around the MJO convection centers. Compared to a geographically fixed base point commonly used for composite and lagged regression analyses, a movable (or Lagrangian) base point locked to wave propagation is better suited for tracing the spatial structure directly coupled with the ISOs. The composite analysis of Benedict and Randall (2007), using a spatially flexible base point fixed at the observed rainfall maximum, was successful in delineating the thermodynamic structure associated with the MJO. Statistical significance is estimated at each location in the composite domain based on the Student's $t$ test against the null hypothesis that the composite variable is equivalent to the climatological mean (or zero anomaly). Portions with statistical significances less than $95 \%$ are not plotted.

\section{Results}

\section{a. Variability in space-time spectrum}

Seasonal variability of the ISOs at different latitudes is first outlined based on a frequency-wavenumber analysis. Figure 2 shows the space-time spectra of OLR for different seasons and three meridional bands. Spectral signals are scaled by statistical significance tested against the red noise. The theoretical dispersion relations are depicted in each panel for the Kelvin wave (solid), $n=1$ ER wave (dash-dotted), and the mixed Rossby-gravity (MRG) wave (dashed) for equivalent depths of 5, 20, and $100 \mathrm{~m}$. These dispersion relations were obtained from the solutions derived by Matsuno (1966). The bandpass filters used later for tracking the ISOs are indicated by boxes in Fig. 2 .

The MJO is easily recognized across all tropical latitudes and seasons. The MJO signal has a distinct peak at wavenumbers of 1-3 in austral summer, which past 

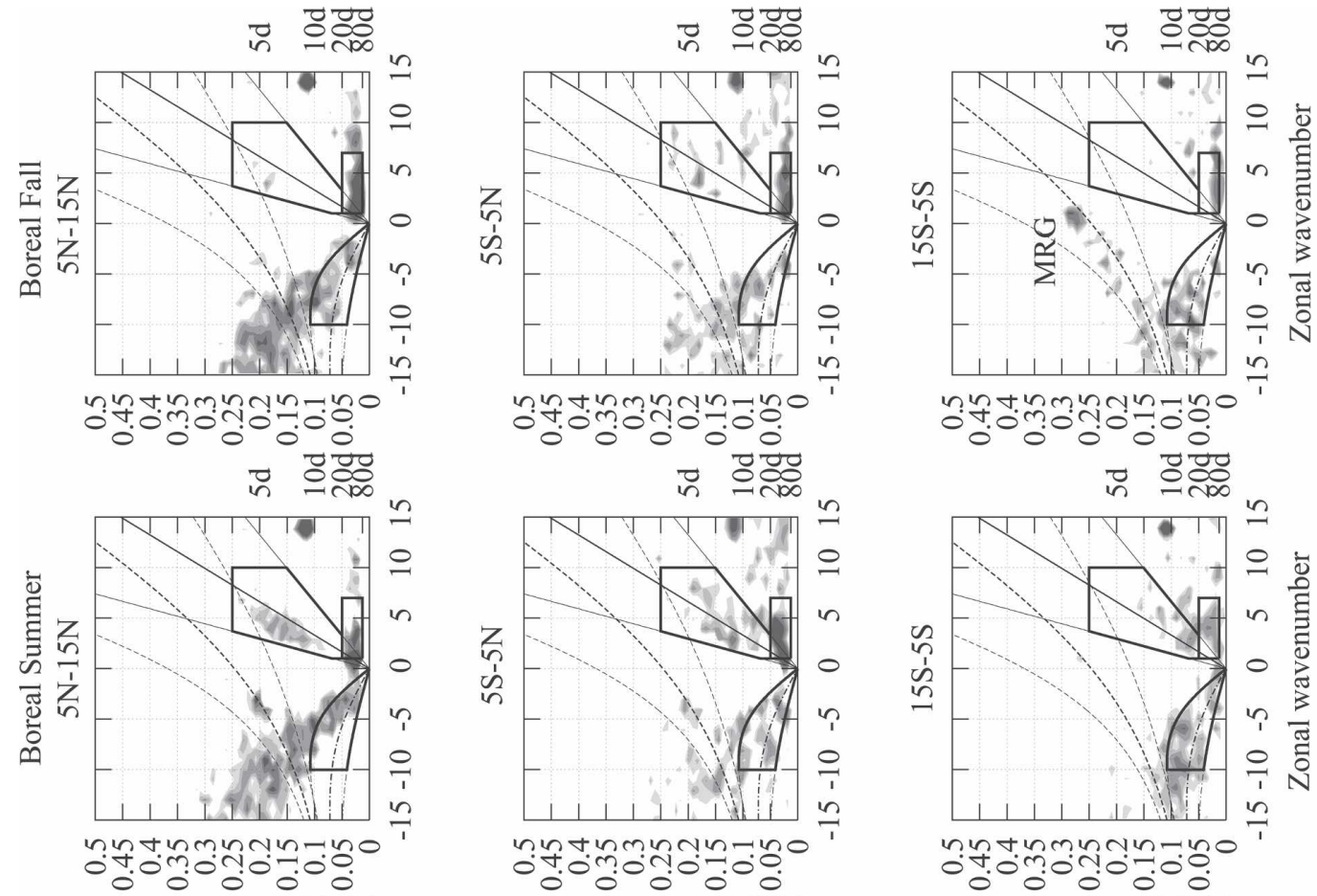

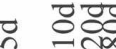

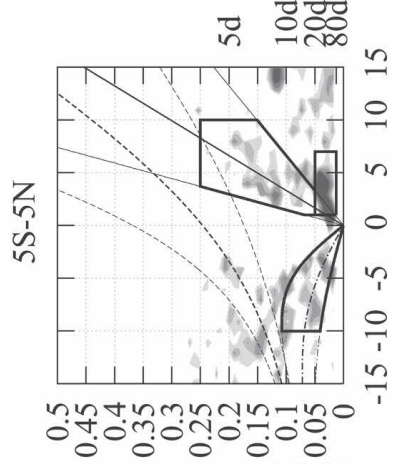

in

$\overline{0}$ 要

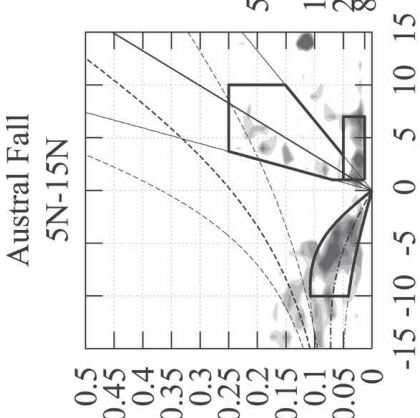

| | | | | n

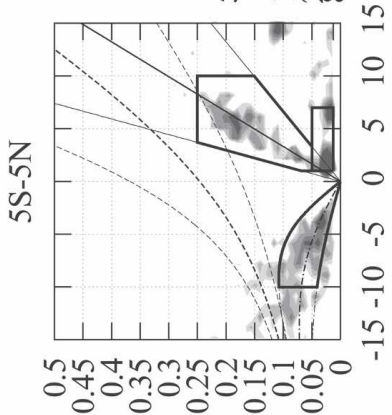

in

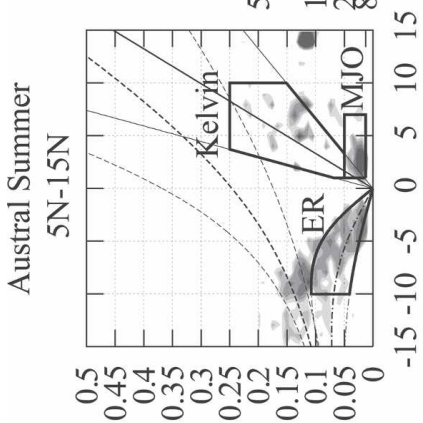

in

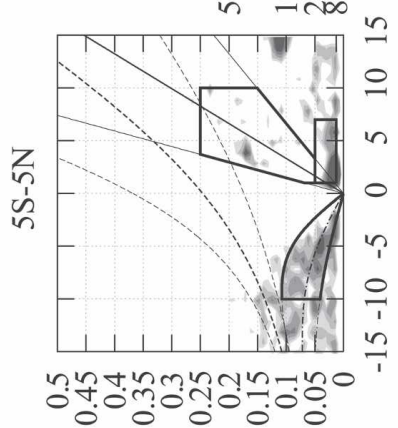

[pdo] Кэuənbə.เ

[pdo] Кэuənbə.ป

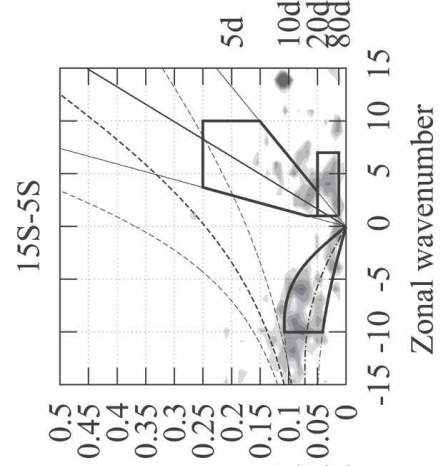

in 预空

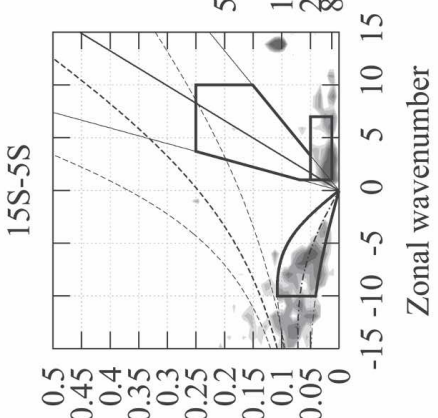

ㅇํㅇ ㅇํㅇ

:

son

ㅁำ

政

㻤

s.

홍

क을 즐

웅

oิ

ज़

诃

这

혈

政

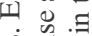

政

o

$\therefore$

월

ลे एँ

密总

ก

월

$\infty$ 可 :

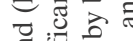

次

की 50 近

용

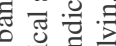

西

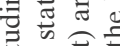

总导苞

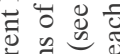

氙苛泀

.

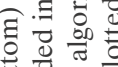

응 of

0 .

Оิ

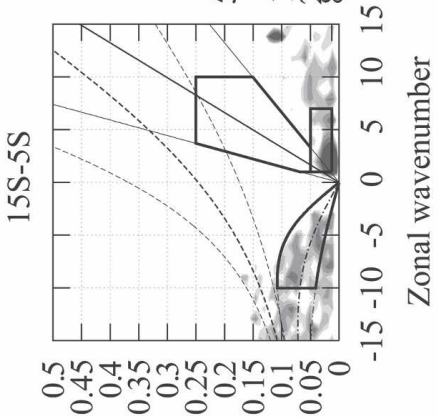

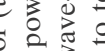

줄

0 o

ते की

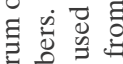

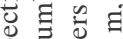

की

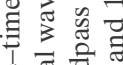

ปี

[pd॰] Кэuәnbə.ॅ

के ली

ஸे ญें

空 
studies pointed out is the primary peak season of the MJO (e.g., Madden 1986; Gutzler and Madden 1989; Zhang and Dong 2004; Roundy and Frank 2004a). A separate high-wavenumber component $(k>5)$ appears in austral fall, possibly making the MJO more dispersive and thus more quickly broken as it propagates. It is, however, noted that the high-wavenumber modes are exaggerated rather than actual, since the spectral power is normalized by the red-noise spectrum. The MJO in the Southern Hemisphere weakens in boreal summer and fall. The Kelvin wave is most prominent in austral fall, with its spectral power concentrated around the equator as expected by the linear theory (Matsuno 1966). The Kelvin wave remains active through boreal summer, but its amplitude is somewhat shifted away from the equator in the Northern Hemisphere. This off-equatorial maximum of the Kelvin wave is related to the seasonal migration of ITCZ as will become clear later. Kelvin wave signals are less significant in austral summer and boreal fall.

The ER wave, observed regardless of latitudes and seasons, is the only constituent of westward-propagating low-frequency waves in austral summer and fall. On the other hand, another westward mode spread over a broad spectral domain emerges in boreal summer and fall. This mode likely corresponds to the tropical depression (TD)-type disturbance (Takayabu and Nitta 1993), as well as the MRG wave where its dispersion relation overlaps, as discussed in the literature (Wheeler and Kiladis 1999; Roundy and Frank 2004a). The Southern Hemisphere in boreal fall shows clear evidence for the MRG wave distinct from any other spectral modes. This is consistent with the result of Hendon and Liebmann (1991), who found the MRG wave most active in boreal fall. A confined peak at the wavenumber of 14 and the cycle of $\sim 9$ days is an artifact due to the spatial and temporal regularity in satellite sampling (Wheeler and Kiladis 1999; Masunaga et al. 2006).

\section{b. Characteristics of individual ISO modes}

The individual ISO modes as tracked in the manner introduced in section 2 are next investigated. Figure 3 depicts the frequency of occurrence of ISO events together with unfiltered OLR flux as a function of longitude. The frequency of occurrence (defined from the number of days with the ISO convection centers observed during the entire period studied) and OLR are zonally smoothed by $\pm 15^{\circ}$ moving average because smaller-scale fluctuations are ignored in the tracking algorithm. Overall, the ISOs are most active from the Indian Ocean through the central Pacific $\left(60^{\circ} \mathrm{E}-180^{\circ}\right)$. The secondary peak appears in the Atlantic Ocean

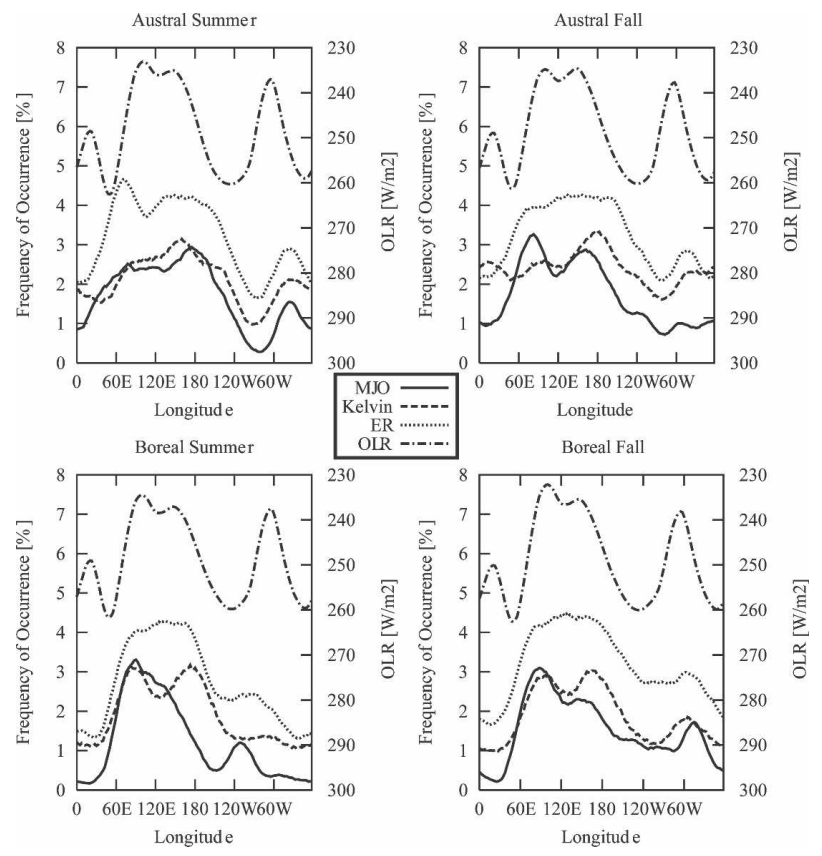

FIG. 3. Frequency of occurrence (labeled on the left ordinate) for the MJO (solid), Kelvin wave (dashed), and ER wave (dotted) convection centers as well as unfiltered OLR flux (dot-dashed, labeled on the right ordinate) as a function of longitude. Different panels are for different seasons.

around $30^{\circ} \mathrm{W}$, most clearly in austral summer, but is completely missing in boreal summer. ISO activity tapers off to minima near $0^{\circ}$ and/or in the west of $60^{\circ} \mathrm{W}$, most likely due to the influence of the African and South American continents (Knutson and Weickmann 1987).

In addition to these general features, the ISOs show notable seasonal variations in the frequency of occurrence. In austral summer, the MJO forms a plateau extending from $60^{\circ} \mathrm{E}$ to the date line. The Kelvin wave also exhibits a plateau closely following the MJO. The MJO plateau is decomposed into a pair of narrower peaks at $80^{\circ}$ and $160^{\circ} \mathrm{E}$ in austral fall. The second peak in the Pacific Ocean disappears in boreal summer, leaving behind a single maximum in the Indian Ocean with a gradually declining shoulder in its east. The absence of the second MJO peak sharply contrasts with the double-peaked distribution of the Kelvin wave in the same season. The boreal summer MJO exhibits a weaker, separate group in the east Pacific $\left(120^{\circ} \mathrm{W}\right)$ as well. The boreal fall ISOs show an intermediate feature between the preceding and following seasons. The ER wave exhibits a pattern generally similar to the other two ISO modes. A notable difference is, however, that the plateau between $60^{\circ}$ and the date line stays throughout a year for the ER wave without being decomposed into separate peaks. 

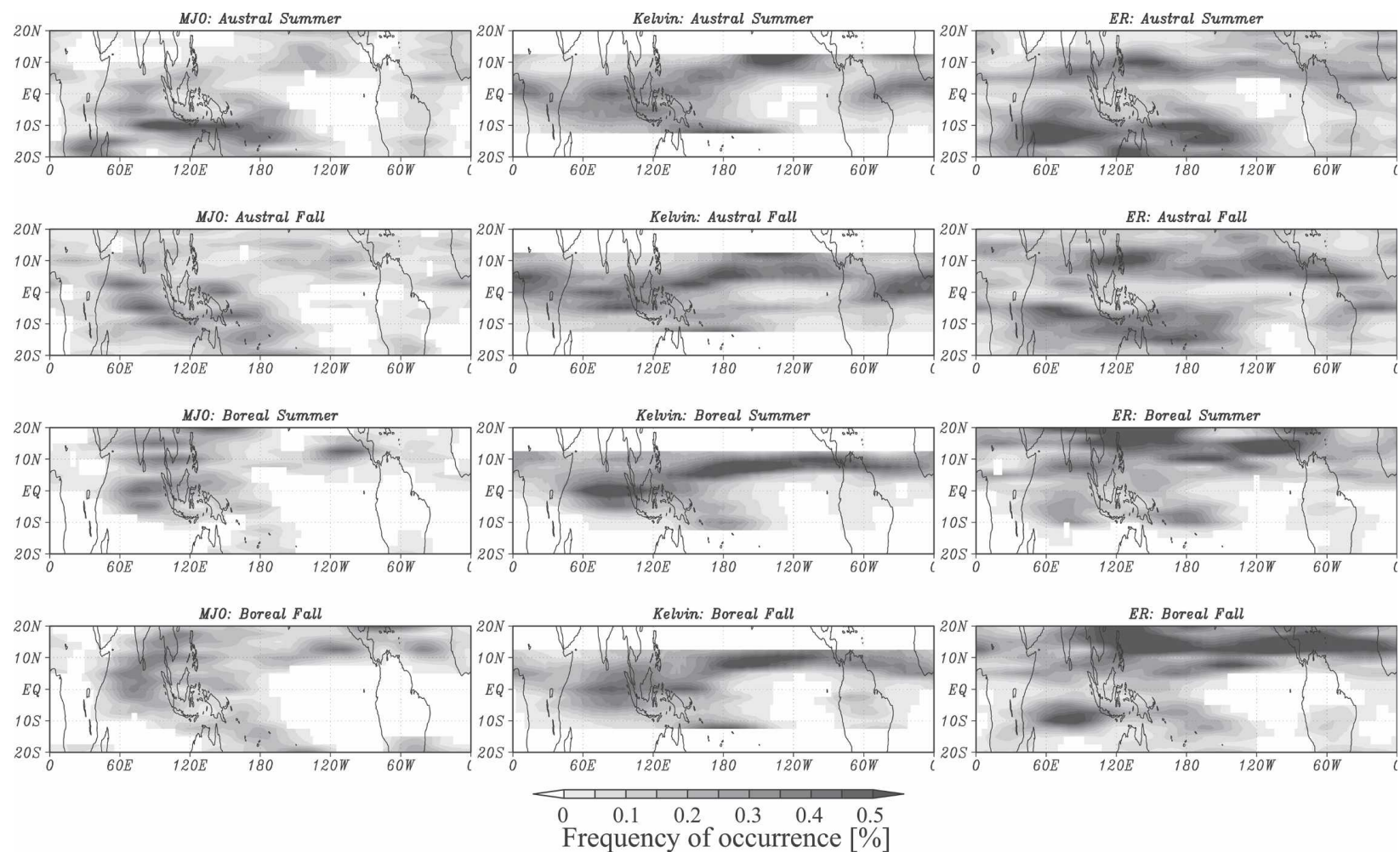

FIG. 4. The global distribution of the (left) MJO, (middle) Kelvin wave, and (right) ER wave convection centers in the frequency of their occurrence. Different panels (top to bottom) are for different seasons.

The fundamental feature of unfiltered OLR is quite steady throughout the year. OLR is coldest over the Indo-Pacific warm pool with a slight dip on the Maritime Continent $\left(120^{\circ} \mathrm{E}\right)$. Secondary peaks are located in Africa and South America, as opposed to the ISOfiltered OLR, which is least active over the continents. This indicates that deep convection developing on tropical Americas and Africa has little connection with large-scale organization associated with the ISOs.

To further investigate these features, the frequency of ISO occurrence is plotted on a global map (Fig. 4). The austral summer MJO appears to prefer a narrow channel around $10^{\circ} \mathrm{S}$ between Indonesia/New Guinea and Australia from the Indian Ocean to eventually reach SPCZ. This branch is mainly responsible for the MJO plateau seen in Fig. 3. Together with another (less conspicuous) branch leading to the northern Pacific through the north of the Maritime Continent, typical MJO trajectories in austral summer resemble the "N(S)E mode" identified by Wang and Rui (1990b). It is noted that the northwestern Pacific MJO, propagating nearly northward as described by Wang and Rui (1990b), is probably not well detected in this study. In austral fall, MJO paths constitute a major group in the Indian Ocean and another in the west Pacific with a local minimum over the Maritime Continent as was evident in Fig. 3. The "EE mode" defined by Wang and Rui (1990b) well shares basic characteristics with the austral fall MJO. A local minimum of MJO activity over the Maritime Continent drew the attention of many authors in the literature (e.g., Salby and Hendon 1994; Zhang and Hendon 1997; Kemball-Cook and Weare 2001).

The MJO is strictly limited in the east of the central Pacific in boreal summer, aside from a separate signal confined in the eastern Pacific ITCZ as also recognized by Knutson and Weickmann (1987). The disappearance of the Pacific peak in this season (Fig. 3) reflects this weakened MJO activity in the west Pacific and SPCZ. ISO propagation has been known to have a notable northward component over the Indian Ocean and subcontinent since early work by Yasunari (1979, 1980, 1981) in association with the active and break cycle of the South Asian summer monsoon. The boreal summer MJO indeed exhibits a considerable northward extension from the equatorial Indian Ocean across the Bay of Bengal in Fig. 4, although it seems composed of separate bands rather than continuous northward development. Sampling bias may be responsible for the apparent discontinuity, because the bandpass filters used 
here do not detect any northward propagation unless it is accompanied with a zonal component. Eastward propagation is present or absent in association with the northward movement, depending systematically on the phase of the ISO cycle (Lau and Chan 1986; Lawrence and Webster 2002). The presence of gaps could be also because the northward migration of cloud systems is not meridionally uniform in this area (Sikka and Gadgil 1980). It is also noted that meridional scale is exaggerated compared to zonal scale in Fig. 4, which makes the latitudinal gaps look wider than actual. The general properties possessed by the boreal summer MJO are still observed in boreal fall, except that eastward penetration into the SPCZ starts to develop again.

The Kelvin wave exhibits a relatively consistent geographical pattern throughout the year. A Kelvin wave signal in the Indian Ocean shifts slightly in the north as it proceeds eastward in the west Pacific to eventually join the Pacific ITCZ. The Kelvin wave weakens in the east Pacific (near $90^{\circ} \mathrm{W}$ ) in austral summer (Fig. 3). The Kelvin wave tends to propagate across a wider zonal extent in austral fall, which makes a stronger spectral signal in the Kelvin wave domain for austral fall than for austral summer (Fig. 2). The Kelvin wave in the Atlantic Ocean through central Africa constitutes a separate group in austral summer and fall, while the Kelvin wave seems to be directly extended from the Pacific ITCZ to the Atlantic Ocean across South America in boreal summer and fall. Notable is the asymmetry about the equator in the global distribution, unlike the theoretical eigenfunctions of the equatorial waves. The absence of symmetry in Kelvin wave convection, also pointed out by Straub and Kiladis (2002) and Roundy and Frank (2004a), suggests that regionality in the background states such as SST and atmospheric dynamical fields plays a crucial role in modulating the moist processes coupled with the large-scale waves.

The ER wave has broad maxima in the southern Indian Ocean and SPCZ as well as in the west Pacific in austral summer. The off-equatorial maxima in each hemisphere are as theoretically expected, although meridional asymmetry is prominent here again. The ER wave becomes more frequent in the Northern Hemisphere across the Pacific Ocean and less frequent in the Southern Hemisphere as seasons change to boreal summer.

\section{c. Dynamical structure associated with the ISOs}

Seasonal variability of the ISOs is further examined in terms of the associated dynamical fields in this section. Figure 5 demonstrates geopotential height (shaded), horizontal winds (vectors), and horizontal convergence (contours) anomalies at $850 \mathrm{hPa}$ composited with respect to each of the three ISO modes. To obtain these diagrams, the ISO bandpass filters used to identify the convection centers (i.e., boxes in Fig. 2) are not applied directly to the space-time fields of geopotential height and horizontal winds. Nevertheless, distinct dynamical features specific to each ISO mode manifest themselves in the composite diagrams as described below. This implies that the ISO convection center used as the base point for compositing procedure is efficient at capturing the associated dynamical fields.

The composite MJO in Fig. 5 shows the basic dynamical characteristics well recognized in the literature (Zhang 2005): low-level easterlies to the east, westerlies to the west, and a pair of cyclonic circulations off the equator to the west of the MJO convection center, that is, $0^{\circ}$ in abscissa by definition. This combined Rossby and Kelvin structure is most striking for the austral summer MJO, associated with strong low-level convergence confined in the Southern Hemisphere. The combined Rossby and Kelvin pattern retains also in the other seasons, although Rossby wavelike gyres are less prominent in boreal summer and fall at least within the meridional range investigated.

The horizontal wind field of the Kelvin wave at 850 $\mathrm{hPa}$ closely follows the shallow-water solution: wind anomaly is predominantly zonal and the amplitude declines poleward from the equator. The overall structure is nearly symmetric about the equator and shows little annual variability. The meridional symmetry in the Kelvin wave dynamical field exhibits a remarkable contrast to the asymmetry in Kelvin-filtered OLR as mentioned earlier. This contrast seems to imply that the atmospheric response to Kelvin wave convection closely follows the linear theory even though convective heating is not symmetrically distributed about the equator. A similar observational result was also obtained by Straub and Kiladis (2002). Some discrepancies from the inviscid wave theory, however, are recognizable in the composite Kelvin wave structure. For example, the convergence maximum is not precisely collocated with the convection center but leads convection in its east by $\sim 10^{\circ}$. The negative anomaly field of geopotential height, furthermore, is latitudinally tilted to the west. The departure from the shallow-water structure will be discussed later in section 4 .

A cyclonic gyre to the west and an anticyclonic counterpart to the east together characterize the composite ER wave structure. A pair of gyres is observable in each hemisphere as theoretically predicted although the amplitude is greater in the summer hemisphere than in the winter hemisphere.

A composite diagram for the upper-tropospheric dy- 

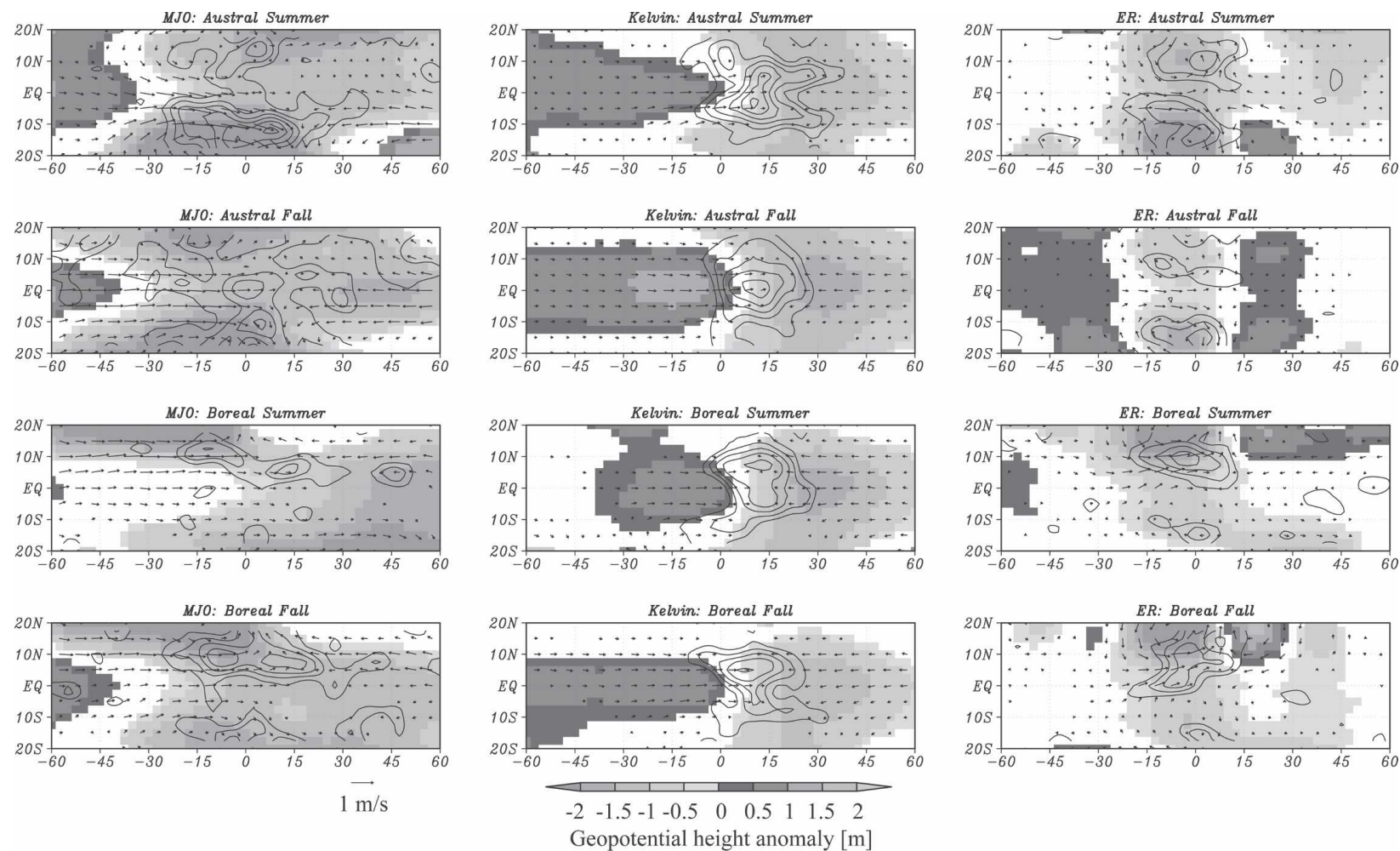

FIG. 5. Composite diagrams of 850 -hPa geopotential height (shaded) and horizontal wind anomalies for the (left) MJO, (middle) Kelvin wave, and (right) ER wave. Darker (lighter) shade represents positive (negative) geopotential height anomalies. Different panels (top to bottom) are for different seasons. Horizontal axis is zonal coordinate relative to the base point or ISO convection center (see text). Contour is anomalous horizontal convergence at the same pressure level, drawn at intervals of $5 \times 10^{-8} \mathrm{~s}^{-1}$ for positive convergence only. Wind and geopotential height are not plotted where local statistical significance is lower than the $95 \%$ level.

namical field at $200 \mathrm{hPa}$ and OLR anomaly is provided in Fig. 6. The lower- and upper-tropospheric fields of the MJO are nearly $180^{\circ}$ out of phase as reported since the earliest work (Madden and Julian 1971, 1972), suggesting the predominance of baroclinic modes. The dominant baroclinic structure is also evident for the Kelvin wave. Irregular disturbances resembling the Rossby wave intruding into the upper-tropospheric field in the winter hemisphere presumably arise from subtropical jet activity (Straub and Kiladis 2003a). The composite OLR anomaly has a spatial pattern in phase with the 200-hPa divergence field (not shown), suggesting that the upper-tropospheric divergence peak is centered on the convection maximum, as consistent with the result of Kiladis et al. (2005).

The baroclinic structure is not as clear for the ER wave. A cyclonic (anticyclonic) circulation at $850 \mathrm{hPa}$ spatially matches with an anticyclonic (cyclonic) gyre at $200 \mathrm{hPa}$ only in the boreal summer Northern Hemisphere. The vertical structure of the ER wave is otherwise heavily tilted, where the upper- and lowertropospheric Rossby structures are roughly in quadrature or almost barotropic in austral summer and fall. A barotropic ER wave was also observed by Kiladis and Wheeler (1995) and Wheeler et al. (2000). The barotropic ER wave might result from the vertical shear in mean zonal wind, which invokes a coupling between barotropic and baroclinic ER modes (Wang and Xie 1996).

\section{d. Relationship of the MJO with the Kelvin and ER waves}

The combined Rossby and Kelvin structure is typical of the composite MJO (Figs. 5 and 6), similar to the steady solution of heat-induced atmospheric response (Gill 1980). The Kelvin and ER waves together, in addition, have been examined in the context of the driving mechanism of MJO propagation (e.g., Salby et al. 1994). Several observational studies have pointed out the possibility that interactions between multiple equatorial waves could play an important role in MJO propagation (e.g., Dunkerton and Crum 1995; Straub and Kiladis 2003b; Roundy and Frank 2004b). While different authors investigated different modes to shed light on different aspects of MJO propagation, the present paper focuses on the roles of the Kelvin and ER 

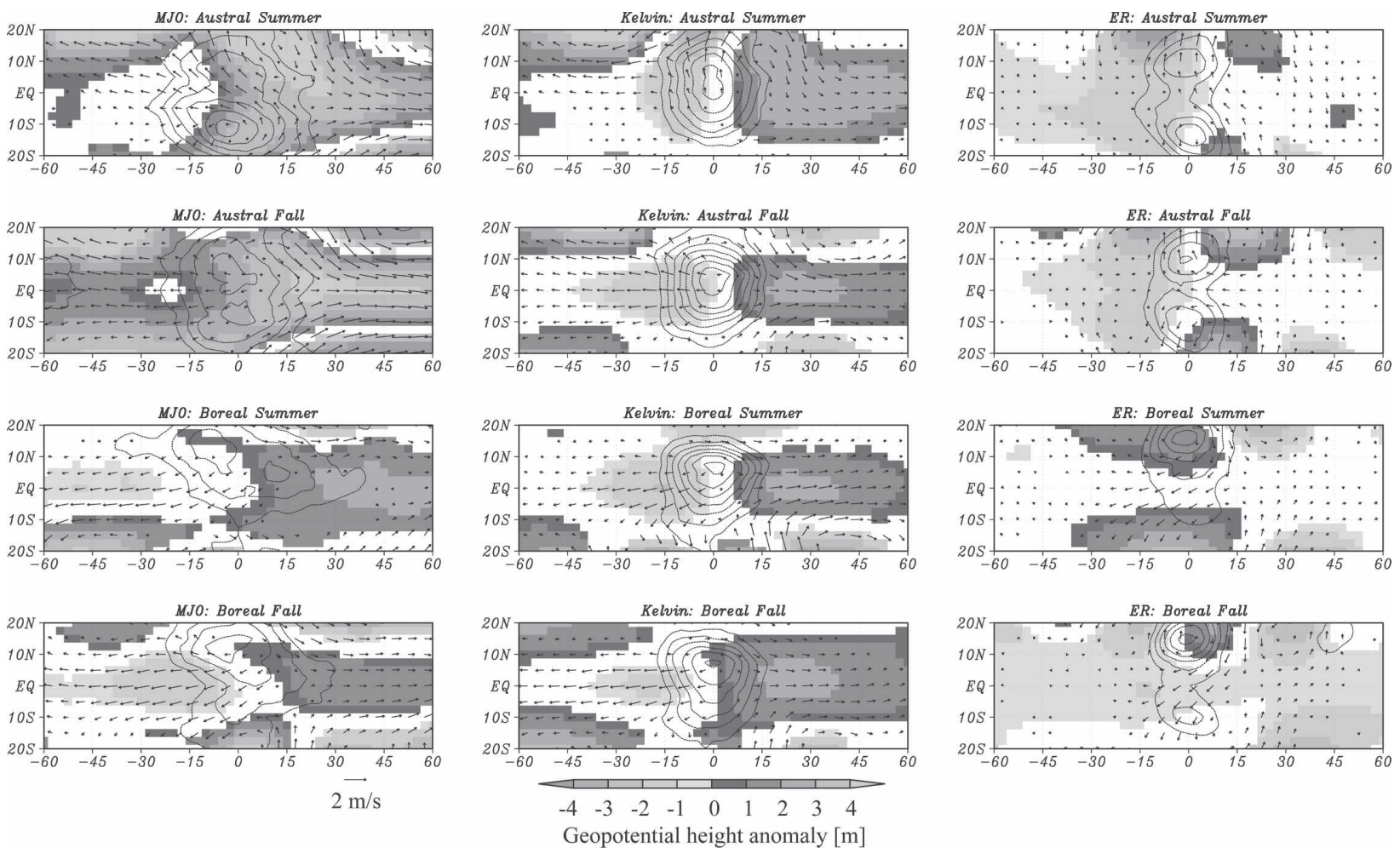

FIG. 6. Same as in Fig. 5 but for 200 hPa. Horizontal convergence has been replaced with the composite OLR anomaly, contoured every $2 \mathrm{~K}$ where negative.

waves. In this subsection, a lagged composite analysis is applied to the Kelvin- and ER-filtered OLR variances with respect to the MJO convection centers in an attempt to explore the relationship among the different ISO modes.

Figure 7 shows the lagged composite diagram for different seasons. Portions with local statistical significances lower than $95 \%$ are blanked out. In austral summer, the Kelvin wave power is concentrated around the equator and is limited to the west of the MJO convection center on day -10 . The Kelvin wave peak moves closer to the MJO convection center on day 0 . The Kelvin wave is spread across a wide zonal range on day +10 . The composite ER wave exhibits no notable change throughout this 20-day sequence, with a pair of zonally broad maxima on both sides of the equator that are roughly centered on the MJO convection center. These results are consistent with a preceding study based on a $2.5-\mathrm{yr}$ record of precipitation data by Masunaga et al. (2006).

The Kelvin wave is much larger in amplitude during austral fall than is in austral summer, as found in the frequency-wavenumber space (Fig. 2). The composite temporal evolution is otherwise qualitatively in parallel with what is observed for austral summer. In contrast, boreal summer and fall are quite different from the other two seasons. The Kelvin wave has the outstanding component emanating to the east of the MJO convection center, while there is no strong sign of an incident Kelvin wave in advance of the maximum MJO activity. Straub and Kiladis (2003b) observed a similar structure of the Kelvin wave in association with the boreal summer MJO. The ER wave has a timeindependent, broad maximum off the equator similar to the result for the preceding seasons, but is limited in the Northern Hemisphere during boreal summer and fall.

The temporal evolution of the Kelvin and ER waves in reference to the $\mathrm{MJO}$ is further examined in the composite time-longitude diagram shown in Fig. 8. The zonal cross section of the Kelvin (ER) wave at the equator $\left(10^{\circ} \mathrm{N}\right)$, around which each wave reaches the maximum in amplitude, is used to plot Fig. 8. The Kelvin wave component approaching from the west of the MJO convection center, as implied by the day -10 diagram in Fig. 7, is traceable along the ridge of the composite Kelvin wave in austral summer and fall. The propagation speed of the composite Kelvin wave is estimated from the inclination of the Kelvin wave ridge in Fig. 8 as approximately $4^{\circ}$ day $^{-1}$. This is roughly consistent with the Kelvin wave speed of $11^{\circ} \mathrm{day}^{-1}$ 

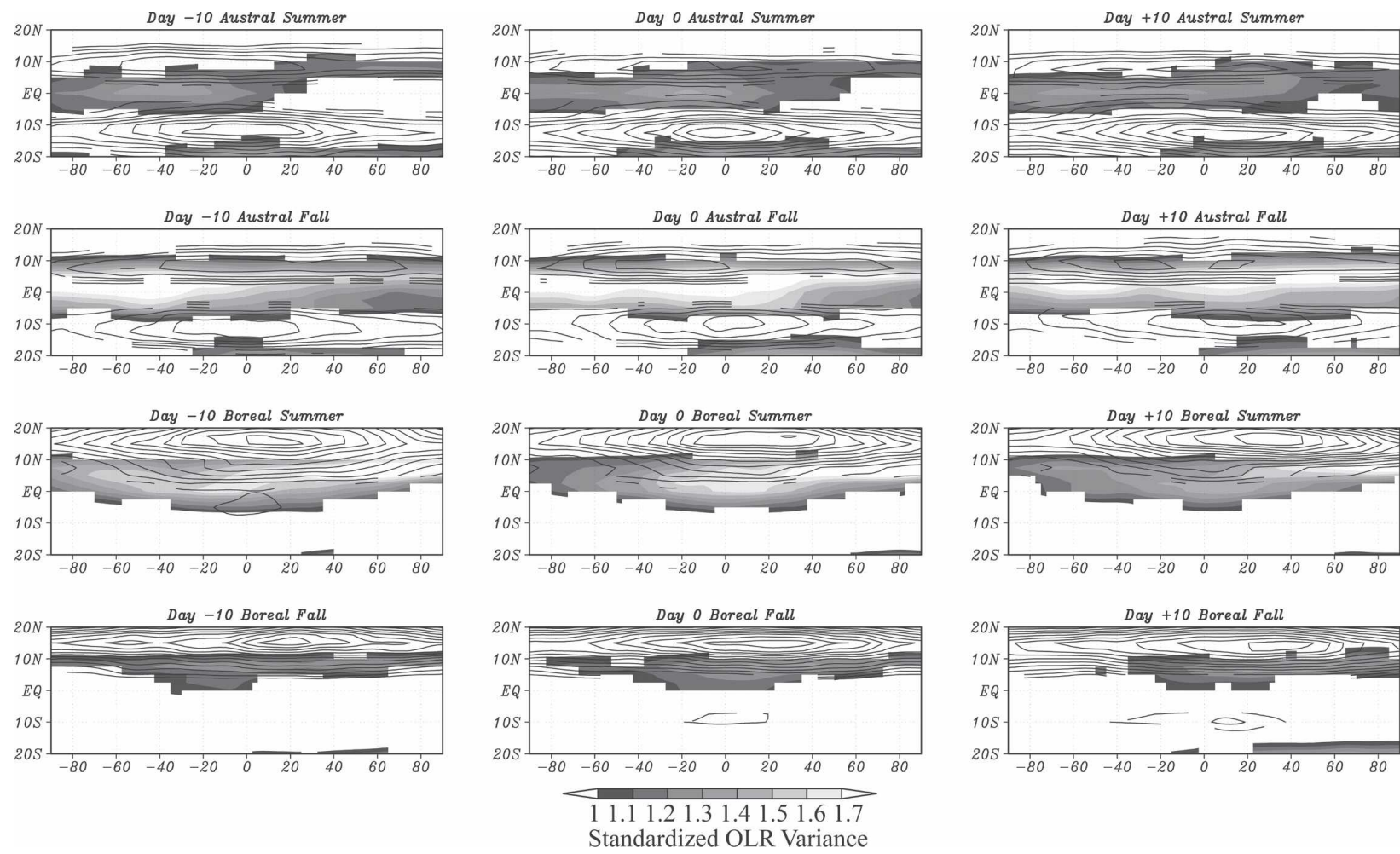

FIG. 7. Filtered OLR variance for the Kelvin and ER waves composited with respect to the MJO convection center, lagged by (left) -10 , (middle) 0 , and (right) +10 days. Different panels (top to bottom) are for different seasons. OLR variance is standardized by the all-season mean variance, or 86.2 and $85.9 \mathrm{~W}^{2} \mathrm{~m}^{-4}$ for the Kelvin and ER waves, respectively. The composite Kelvin wave is shaded while the ER wave is contoured at intervals of 0.1 starting at 1.1. The composite Kelvin and ER waves are plotted only where local statistical significance is greater than $95 \%$.

$(=\sqrt{g h}$ for $h=20 \mathrm{~m})$ relative to the MJO convection center moving at $7^{\circ}$ day $^{-1}$, which corresponds to the wavenumber- 1 mode with the period of 50 days. In boreal summer, on the other hand, the Kelvin wave power tends to be concentrated near the MJO convection center with weaker evidence of the approaching component. The approaching Kelvin wave completely vanishes in boreal fall. A systematic trend of ER wave propagation is unclear throughout the year. The amplitude maximum of the ER wave mostly stays around the MJO convection center, although short-lived segments of westward propagation are barely recognized, particularly in boreal fall.

Figure 9 shows a composite time-longitude diagram constructed from all-season data but regionally isolated for the Indian Ocean $\left(20^{\circ} \mathrm{S}-10^{\circ} \mathrm{N}, 50^{\circ}-100^{\circ} \mathrm{E}\right)$ and the west and central Pacific Ocean $\left(20^{\circ} \mathrm{S}-10^{\circ} \mathrm{N}, 150^{\circ} \mathrm{E}-\right.$ $\left.150^{\circ} \mathrm{W}\right)$. In the Indian Ocean, both the Kelvin and ER waves are consistently weak in the west of MJO convection, as expected by Figs. 3 and 4 where the ISOs are constantly inactive over Africa. In the Pacific Ocean, in contrast, the Kelvin wave propagating toward the MJO convection center is evident, while no emanating com- ponent exists farther east. The seasonal and regional contrasts in the changing roles of the Kelvin wave will be discussed in section 4 below.

\section{Discussion and conclusions}

Many theories have been proposed over decades to physically interpret the slow, eastward propagation and periodicity of the MJO (see reviews by Wang 2005 and Zhang 2005). While some of them are successful in explaining certain aspects of the $\mathrm{MJO}$, no single theory to date is satisfactorily comprehensive to elucidate a variety of diverse properties of MJO mechanism. In this section, possible physical processes involved in the MJO are discussed as inferred from the present findings.

An intriguing implication of the current analysis is that the Kelvin wave leads the MJO as it approaches from the west, while the Kelvin wave extends further to the east of MJO convection at a later phase of the MJO life cycle (Figs. 7 and 8). The leading component of the Kelvin wave is well established in the Pacific Ocean, while it is only barely discernible in the Indian Ocean 

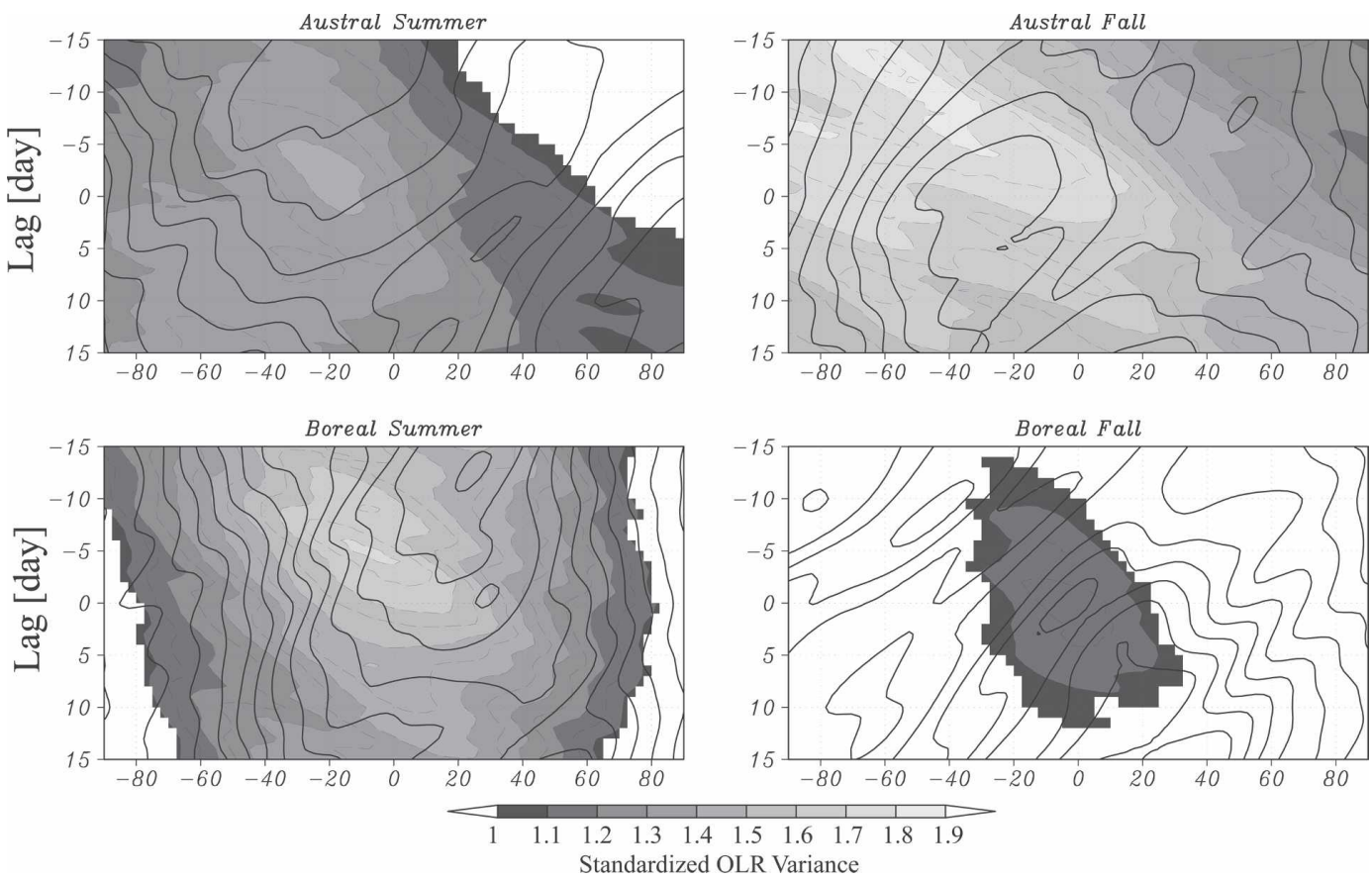

FIG. 8. Time-longitude diagram of filtered OLR variance for the Kelvin (ER) waves at the equator $\left(10^{\circ} \mathrm{N}\right)$ composited with respect to the MJO convection center with lags from -15 to 15 days. Different panels are for different seasons. OLR variance is standardized by the all-season mean variance as done for Fig. 7. The composite Kelvin wave is shaded and contoured (dashed) while the ER wave is contoured in solid lines. Contour is drawn at the interval of 0.05 starting at 1.1. The composite Kelvin and ER waves are plotted only where local statistical significance is greater than $95 \%$.

(Fig. 9). In this section, the role of the Kelvin wave in MJO propagation is discussed in further detail.

\section{a. MJO propagation}

Low-level convergence was found to slightly lead convection and, on the other hand, upper-level divergence precisely overlies convection for the observed Kelvin wave (section 3c). Such a westward vertical tilt in the convergence field is as predicted for a Kelvin mode in the presence of boundary layer convergence due to surface friction. A theoretical framework of the frictional wave-conditional instability of the second kind (CISK) or frictional convergence feedback was originally developed for equatorially trapped waves by Wang (1988). Wang (1988) showed that wave-induced convergence and frictional convergence working together suppress local convective instability but could amplify planetary-scale modes of the moist Kelvin

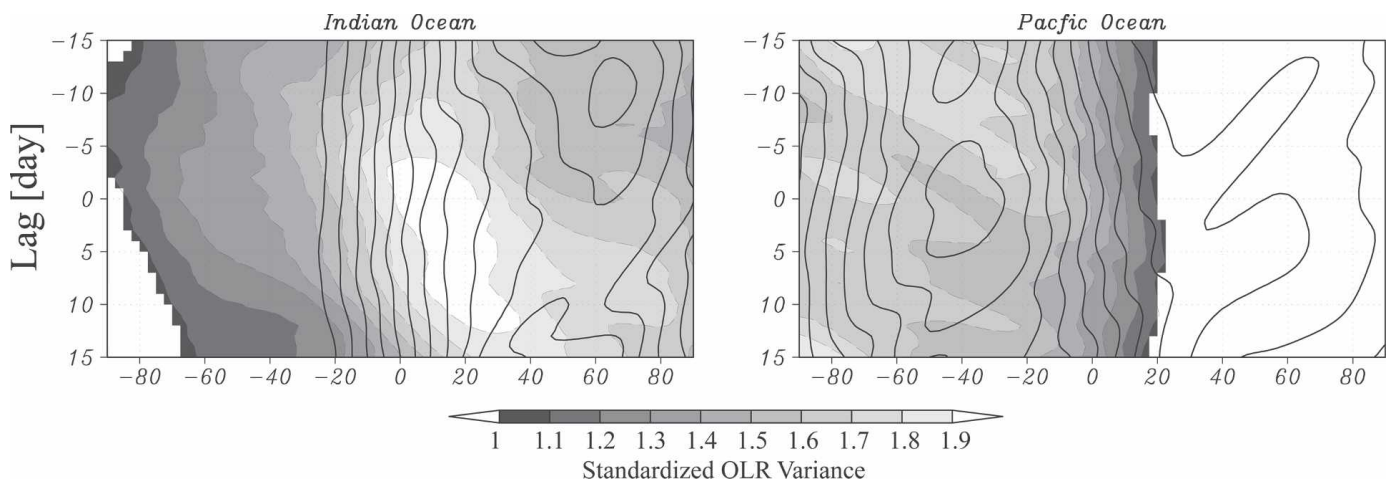

FIG. 9. Same as in Fig. 8 but for selected geographical regions. (left) Diagram composited with respect to the MJO convection centers located in the Indian Ocean $\left(20^{\circ} \mathrm{S}-10^{\circ} \mathrm{N}, 50^{\circ}-100^{\circ} \mathrm{E}\right)$. (right) The western and central Pacific Ocean $\left(20^{\circ} \mathrm{S}-10^{\circ} \mathrm{N}, 150^{\circ} \mathrm{E}-150^{\circ} \mathrm{W}\right)$. Contour interval is 0.1 . 
wave. The meridional tilt in Kelvin-composite geopotential anomaly (Fig. 5) is also reminiscent of the pattern simulated in frictional wave-CISK models (e.g., Fig. 5 of Wang and Li 1994). More recent studies based on refined frictional wave-CISK models discovered diverse results in terms of growth rate and scale selection but all agreed in the overall dynamical structure of the frictionally modified Kelvin wave (Wang and Rui 1990a; Xie and Kubokawa 1990; Salby et al. 1994; Ohuchi and Yamasaki 1997; Moskowitz and Bretherton 2000).

Boundary layer convergence associated with each ISO mode is depicted in Fig. 10, where composite 1000$\mathrm{hPa}$ convergence anomaly is shown. It is noted that surface winds largely depend on model-specific dynamics in the reanalysis dataset and represent observations only to this extent. The Kelvin wave convergence has the maximum on the equator leading the convection center by $\sim 15^{\circ}$, similar to the $850-\mathrm{hPa}$ convergence field (Fig. 5). Unlike 850-hPa convergence, however, Fig. 10 exhibits tongues of boundary layer convergence extending from the equatorial maximum to its poleward west. Theoretical studies of the frictionally modified Kelvin wave indeed imply the presence of an offequatorial component of boundary layer convergence [e.g., Fig. 9e of Wang and Rui (1990a), in terms of vertical motion at the boundary layer top, and Fig. 9c of Salby et al. (1994)]. It does not contradict the absence of the corresponding off-equatorial feature in the 850hPa Kelvin wave convergence (Fig. 5), given that ISO convergence field has a strong vertical gradient from the surface to the $850-\mathrm{hPa}$ level (Hendon and Salby 1994; Kiladis et al. 2005). In austral summer, a tongue of convergence develops down to $15^{\circ} \mathrm{S}$, where it forms a distinct peak. This off-equatorial peak of Kelvin wave surface convergence is collocated with the surface convergence maximum of the ER wave. The Kelvin wave is therefore potentially interactive with the ER wave to reinforce frictional convergence when convection centers associated with the two waves encounter each other. It is further suggested that such collaborative enhancement of boundary layer convergence, if it occurs, may have some physical connection with the MJO, given that the MJO-composited 1000-hPa convergence is also in harmony with the Kelvin and ER wave convergence.

This hypothetical relationship of the MJO with the Kelvin and ER waves does not contradict the lagged composite analysis outlined in section $3 \mathrm{~d}$. Figure 7 shows that the ER wave power is in general loosely concentrated in longitude around MJO convection. The ER wave maximum stays close to the MJO convection center even as early as 10 days before the peak MJO
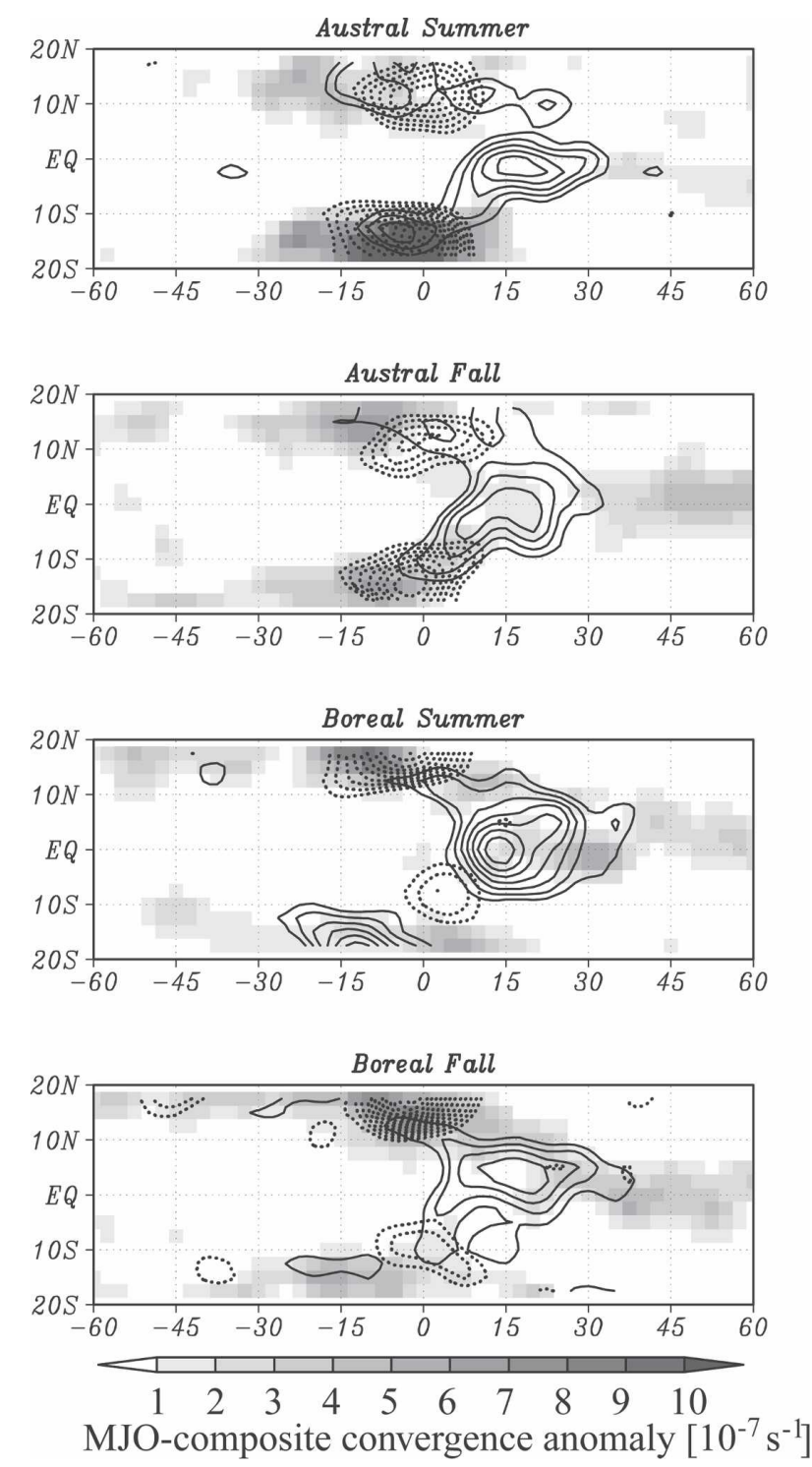

FIG. 10. Horizontal convergence anomaly at $1000 \mathrm{hPa}$ composited with respect to the MJO (shaded), Kelvin wave (solid contour), and ER wave (dashed contour). Contour interval is $5 \times$ $10^{-8} \mathrm{~s}^{-1}$ with only positive convergence drawn. Different panels (top through bottom) are for different seasons.

convection, when the Kelvin wave is still far away to the west in austral summer. This might be translated as a stage when an ER wave "awaits" an incoming Kelvin wave preceding the peak phase of MJO convection. The equatorial maximum of Kelvin wave convergence in the east of convection favors its eastward propagation by accumulating low-level moisture ahead (Hendon and Salby 1994; Maloney and Hartmann 1998; Kiladis et al. 2005). Figure 7 suggests that the Kelvin wave finally arrives to join the ER wave around day 0 , when MJO convection peaks. This is also the time when 
the Kelvin and ER waves are in tandem capable of strengthening boundary layer convergence (Fig. 10). Given this result, the combined Rossby and Kelvin structure in the composite MJO (Fig. 5) can be viewed as a trace of the Kelvin and ER waves met together, while a heat-induced response to MJO convection is probably superposed on it as well. The Kelvin wave, separated away from the ER wave again, is left emanating eastward once the peak phase is passed. The emanating Kelvin wave corresponds to the "propagating response" to MJO convection reported by Salby and Hendon (1994). The ER wave is virtually stationary during the entire cycle.

The frictionally modified Kelvin wave is accompanied with finite meridional wind component off the equator, which, Wang and Rui (1990a) and Salby et al. (1994) argued, probably arises from mode coupling with the Rossby wave. The Rossby-like element inherent in the frictionally modified Kelvin wave is presumably augmented by an ER wave intruding into an incident Kelvin wave. The interference of the ER wave therefore could positively feed back the Kelvin wave through off-equatorial boundary layer convergence. As implied from normal mode analyses and linearized numerical models (Wang and Rui 1990a; Salby et al. 1994; Wang and Li 1994), a frictionally modified Kelvin mode grows in amplitude and lowers in phase speed for SSTs higher than a critical value around $29^{\circ} \mathrm{C}$, where convective heating and large-scale warming are positively correlated, letting them amplify each other. As such, an external trigger brought by interacting Kelvin and ER waves and the wave-intrinsic instability supported by warm sea surface together is capable of giving rise to a convective burst that peaks MJO activity. The quick growth of convection would not be as efficient outside the tropical warm pool because subcritical SSTs damp the frictionally modified Kelvin wave (Wang and Rui 1990a; Salby et al. 1994).

A near-zero group velocity of the ER wave (Wheeler et al. 2000) is a part of the reason why the composite ER wave exhibits little systematic temporal variation. Another plausible factor is that ER wave propagation is likely trapped within a limited zonal span because the frictionally modified ER wave is always a damping mode by itself (Wang and Rui 1990a; Moskowitz and Bretherton 2000). The theoretical implication that frictional convergence works favorably to the Kelvin wave but not to the ER wave seems to dictate the direction of MJO propagation (Wang 2005).

Masunaga et al. (2006) investigated 10 individual MJO events together with the Kelvin and ER waves based on bandpass-filtered precipitation data from the Tropical Rainfall Measuring Mission (TRMM). Their time-longitude analysis discovered a number of cases where the Kelvin wave appears to be interrupted by intruding ER waves with the occasional onset of intensified convective episodes, which occurs within the MJO envelope over the Indo-Pacific warm pool. Kelvin waves approaching from the west and emanating to the east of the MJO envelope are individually visible in their dataset. The "stationary convective phase" they found in the MJO envelope could have been invoked by the unstable growth of a frictionally modified Kelvin mode. No apparent counterpart of the stationary convective phase, however, has been discussed in past theoretical work. This may be because the stationary convective phase is not reproducible by linearized models. Nonlinearity might be indeed crucial for the maintenance of the stationary convection phase, given the result of Oouchi and Yamasaki (2001) who discovered quasi-stationary convection as well as eastwardpropagating convective envelopes in their global-scale two-dimensional cloud-resolving model simulation.

The spatial coherence in boundary layer convergence among the different ISO modes is generally not as evident as found in austral summer (Fig. 10). Even in austral summer, the composite MJO convergence is much weaker in the Northern Hemisphere than in the Southern Hemisphere. The absence of the northern counterpart may be attributed to the colder ocean as well as the larger landmass in the Northern Hemisphere. The austral summer Southern Hemisphere serves as an ideal environment for the frictional destabilization, while otherwise the warmest sector of the tropical oceans tends to be disrupted by land barriers such as the Maritime Continent and Indian subcontinent. This is perhaps a major reason why the $\mathrm{MJO}$ is most active during austral summer (section 3b).

In addition to (and in part because of) the geographical constraint, the MJO in boreal summer and fall typically moves to north or northeast from the Indian Ocean, leaving behind no substantial fraction of the MJO propagating deep into the Pacific Ocean (Fig. 4). The boreal summer/fall MJO is therefore expected to mostly mirror the characteristics in the Indian Ocean and to be scarcely affected by those specific to the Pacific Ocean. This indeed accounts for the seasonal cycle in Fig. 7, where the MJO is not led by the Kelvin wave approaching from the west but only emanates a Kelvin wave to the east in boreal summer and fall. The radiating Kelvin wave contributes, to some extent, to the second maximum near the date line in the zonally double-peaked histogram (Fig. 3). A corresponding peak is missing for the MJO in boreal summer reflecting the fact that the MJO itself rarely propagates down to the central Pacific during this season. 


\section{b. MJO onset}

The absence of a triggering Kelvin wave for the MJO in the Indian Ocean leads to the question of what initiates the MJO there. Whereas the MJO onset is outside the scope of this paper, possible onset mechanisms are briefly reviewed below.

An observational data analysis conducted by Kemball-Cook and Weare (2001) implied a gradual and continuous buildup of moist static energy that guides convection deepening toward the peak MJO activity. They hypothesized that the onset of MJO convection is preconditioned by surface evaporation moistening the boundary layer, followed by the destabilization of the free troposphere through shallow convection, which eventually primes the atmosphere for deep convection. A similar intraseasonal cycle inherent in the oceanatmosphere system is commonly recognized in a number of observations (Lin and Johnson 1996; Zhang 1996; Kikuchi and Takayabu 2004; Stephens et al. 2004; Benedict and Randall 2007; Masunaga et al. 2006). The relevance of such a locally regulated cycle to the MJO has been explored also by modeling studies (e.g., Yamagata and Hayashi 1984; Bladé and Hartmann 1993; Hu and Randall 1994; Sobel and Gildor 2003).

Another potential trigger of the MJO onset could be brought by dry waves. Although convective activity associated with the MJO is localized in the eastern hemisphere, dry atmospheric disturbances can travel beyond the convectively active region (e.g., Milliff and Madden 1996). A dry wave propagating across the globe may take part in triggering the next cycle of the MJO when it arrives back in the Indian Ocean (Knutson and Weickmann 1987; Yanai et al. 2000; Kikuchi and Takayabu 2003). Interaction between eastward- and westwardpropagating ISOs together with partial reflection of the waves from the land barrier over Africa could be another factor that induces MJO convection in the Indian Ocean (Roundy and Frank 2004b). Further investigations have yet to be done to conclude whether (and, if so, how) a dry remnant from the previous convective cycle helps trigger the MJO.

\section{c. Summary}

In summary of the findings from the current analysis, the dynamical processes involved in MJO propagation may be speculated as follows.

The life cycle of the MJO starts with the onset over the Indian Ocean, followed by its propagation to the east. In austral summer, the Kelvin wave is involved in the eastward propagation of the MJO preceding its peak activity. The MJO convection centers preferably go through the narrow oceanic channel near $10^{\circ} \mathrm{S}$ be- tween Australia and Indonesia/New Guinea to eventually penetrate deep into the Pacific Ocean. When an incoming Kelvin wave encounters an ER wave, the Kelvin and ER waves are allowed to be dynamically linked with each other through off-equatorial boundary layer convergence within the MJO envelope. As expected from the frictional wave-CISK theory, a frictionally modified Kelvin mode can be destabilized over tropical warm pools, capable of seeding intensive convective episodes as it decelerates the eastward propagation. As such, large-scale disturbances amplified jointly by interacting Kelvin and ER waves and by a favorable SST condition lead to a burst of MJO convection, which makes the MJO most distinctive from individual modes of the Kelvin and ER waves.

The austral fall MJO holds most of the propagation characteristics as described for austral summer. The seasonal migration of MJO paths, however, results in a less favorable condition for MJO propagation as the Maritime Continent stands in its way. While the equinoctial SST distribution favors Kelvin wave propagation, its interaction with the ER wave does not work as effectively as in austral summer because frictional moisture convergence is inefficient over a landmass. The oceanic channel in the north of Australia is almost completely shut off for MJO propagation in boreal summer, during which the northward or northeastward propagation to the Asian continent dominates the eastward propagation of the MJO. The overall pattern remains unchanged from boreal summer to fall, although the extensive eastward propagation begins to recover toward the austral summer to come.

There are some related problems unaddressed in the present paper. The mechanism of the northward propagation in boreal summer is beyond the scope of this study, since the bandpass filter we employ is only sensitive to a zonal component of propagation. The role of frictional convergence needs to be quantitatively assessed for its role in explaining the observed MJO structure. The present study does not rule out the potential significance of any other theories. The onset mechanism of the MJO is another outstanding issue, which is critical for understanding the periodicity of the MJO. ENSO-related variability of the MJO was not discussed either in this paper. Although it is unlikely that the MJO is a key agent that regulates ENSO, the MJO and other ISO modes could indirectly contribute to the maintenance of the ENSO cycle (Lau 2005).

Acknowledgments. The author thanks Chris Kummerow and Jim Benedict for reading the manuscript and providing suggestions for improvement. Detailed comments given by anonymous reviewers are also ap- 
preciated. NOAA-interpolated OLR data and NCEPNCAR Reanalysis data were provided by the NOAA Cooperative Institute for Research in Environmental Sciences (CIRES) Climate Diagnostics Center (CDC), Boulder, Colorado, from their Web site at http://www. cdc.noaa.gov/. This research is in part supported by NOAA's office of Global Program Grant NA17RJ1228\#15 and NASA's Precipitation Program Grant NAG5-13694.

\section{REFERENCES}

Benedict, J. J., and D. A. Randall, 2007: Observed characteristics of the MJO relative to maximum rainfall. J. Atmos. Sci., 64, 2332-2354.

Bladé, I., and D. L. Hartmann, 1993: Tropical intraseasonal oscillations in a simple nonlinear model. J. Atmos. Sci., 50, 29222939.

Chang, C.-P., 1977: Viscous internal gravity waves and lowfrequency oscillations in the tropics. J. Atmos. Sci., 34, 901910.

Dunkerton, T. J., and F. X. Crum, 1995: Eastward propagating $\sim 2$ - to 15-day equatorial convection and its relation to the tropical intraseasonal oscillation. J. Geophys. Res., 100, $25781-25790$

Emanuel, K. A., J. D. Neelin, and C. S. Bretherton, 1994: On large-scale circulations in convecting atmospheres. Quart. J. Roy. Meteor. Soc., 120, 1111-1143.

Gill, A. E., 1980: Some simple solutions for heat-induced tropical circulation. Quart. J. Roy. Meteor. Soc., 106, 447-462.

Gruber, A., and A. F. Krueger, 1984: The status of the NOAA outgoing longwave radiation data set. Bull. Amer. Meteor. Soc., 65, 958-962.

Gutzler, D. S., and R. A. Madden, 1989: Seasonal variations in the spatial structure of intraseasonal tropical wind fluctuations. $J$. Atmos. Sci., 46, 641-660.

Hendon, H. H., and B. Liebmann, 1991: The structure and annual variation of antisymmetric fluctuations of tropical convection and their association with Rossby-gravity waves. J. Atmos. Sci., 48, 2127-2140.

- , and M. L. Salby, 1994: The life cycle of the Madden-Julian oscillation. J. Atmos. Sci., 51, 2225-2237.

Hu, Q., and D. A. Randall, 1994: Low-frequency oscillations in radiative-convective systems. J. Atmos. Sci., 51, 1089-1099.

Kalnay, E., and Coauthors, 1996: The NCEP/NCAR 40-Year Reanalysis Project. Bull. Amer. Meteor. Soc., 77, 437-471.

Kemball-Cook, S. R., and B. C. Weare, 2001: The onset of convection in the Madden-Julian oscillation. J. Climate, 14, 780793.

Kikuchi, K., and Y. N. Takayabu, 2003: Equatorial circumnavigation of moisture signal associated with the Madden-Julian Oscillation (MJO) during boreal winter. J. Meteor. Soc. Japan, 81, 851-869.

— associated with the MJO during TOGA COARE IOP: Trimodal characteristics. Geophys. Res. Lett., 31, L10101, doi:10.1029/2004GL019601.

Kiladis, G. N., and M. Wheeler, 1995: Horizontal and vertical structure of observed tropospheric equatorial Rossby waves. J. Geophys. Res., 100, 22 981-22 997.

— K. H. Straub, and P. T. Haertel, 2005: Zonal and vertical structure of the Madden-Julian oscillation. J. Atmos. Sci., 62 , 2790-2809.

Knutson, T. R., and K. M. Weickmann, 1987: 30-60 day atmospheric oscillations: Composite life cycles of convection and circulation anomalies. Mon. Wea. Rev., 115, 1407-1436.

Lau, K.-M., 2005: El Niño Southern Oscillation connection. Intraseasonal Variability in the Atmosphere-Ocean Climate System, Springer-Verlag, 271-305.

— , and P. H. Chan, 1986: Aspects of the 40-50 day oscillation during the northern summer as inferred from outgoing longwave radiation. Mon. Wea. Rev., 114, 1354-1367.

Lawrence, D. M., and P. J. Webster, 2002: The boreal summer intraseasonal oscillation: Relationship between northward and eastward movement of convection. J. Atmos. Sci., 59, 1593-1606.

Lin, X., and R. H. Johnson, 1996: Kinematic and thermodynamic characteristics of the flow over the western Pacific warm pool during TOGA COARE. J. Atmos. Sci., 53, 695-715.

Madden, R. A., 1986: Seasonal variations of the 40-50 day oscillation in the tropics. J. Atmos. Sci., 43, 3138-3158. , and P. R. Julian, 1971: Detection of a 40-50 day oscillation in the zonal wind in the tropical Pacific. J. Atmos. Sci., 28, $702-708$.

_, and _- 1972: Description of global-scale circulation cells in the tropics with a 40-50 day period. J. Atmos. Sci., 29, 1109-1123.

_ and - 1994: Observations of the 40-50-day tropical oscillation-A review. Mon. Wea. Rev., 122, 814-837.

Maloney, E. D., and D. L. Hartmann, 1998: Frictional moisture convergence in a composite life cycle of the Madden-Julian oscillation. J. Climate, 11, 2387-2403.

Mapes, B. E., 2000: Convective inhibition, subgrid-scale triggering energy, and stratiform instability in a toy tropical wave model. J. Atmos. Sci., 57, 1515-1535.

Masunaga, H., T. S. L'Ecuyer, and C. D. Kummerow, 2006: The Madden-Julian oscillation recorded in early observations from the Tropical Rainfall Measuring Mission (TRMM). $J$. Atmos. Sci., 63, 2777-2794.

Matsuno, T., 1966: Quasi-geostrophic motions in the equatorial area. J. Meteor. Soc. Japan, 44, 25-43.

Matthews, A. J., B. J. Hoskins, J. M. Slingo, and M. Blackburn, 1996: Development of convection along the SPCZ within a Madden-Julian oscillation. Quart. J. Roy. Meteor. Soc., 122, 669-688.

Milliff, R. F., and R. A. Madden, 1996: The existence and vertical structure of fast, eastward-moving disturbances in the equatorial troposphere. J. Atmos. Sci., 53, 586-597.

Moskowitz, B. M., and C. S. Bretherton, 2000: An analysis of frictional feedback on a moist equatorial Kelvin mode. J. Atmos. Sci., 57, 2188-2206.

Neelin, J. D., and J.-Y. Yu, 1994: Modes of tropical variability under convective adjustment and the Madden-Julian oscillation. Part I: Analytical theory. J. Atmos. Sci., 51, 1876-1894.

Ohuchi, K., and M. Yamasaki, 1997: Kelvin wave-CISK controlled by surface friction: A possible mechanism of super cloud cluster. Part I: Linear theory. J. Meteor. Soc. Japan, 75, 497-511.

Oouchi, K., and M. Yamasaki, 2001: An MJO-like gravity wave and superclusters simulated in a two-dimensional cumulusscale-resolving model under a warm pool condition. J. Meteor. Soc. Japan, 79, 201-218.

Roundy, P. E., and W. M. Frank, 2004a: A climatology of waves in the equatorial region. J. Atmos. Sci., 61, 2105-2132. 
$\longrightarrow$, and - 2004b: Effects of low-frequency wave interactions on intraseasonal oscillations. J. Atmos. Sci., 61, 3025-3040.

Salby, M. L., and H. H. Hendon, 1994: Intraseasonal behavior of clouds, temperature, and motion in the tropics. J. Atmos. Sci., 51, 2207-2224.

— , R. R. Garcia, and H. H. Hendon, 1994: Planetary-scale circulations in the presence of climatological and wave-induced heating. J. Atmos. Sci., 51, 2344-2367.

Sikka, D. R., and S. Gadgil, 1980: On the maximum cloud zone and the ITCZ over Indian longitudes during the Southwest monsoon. Mon. Wea. Rev., 108, 1840-1853.

Sobel, A. H., and H. Gildor, 2003: A simple time-dependent model of SST hot spots. J. Climate, 16, 3978-3992.

Stephens, G. L., P. J. Webster, R. H. Johnson, R. Engelen, and T. L'Ecuyer, 2004: Observational evidence for the mutual regulation of the tropical hydrological cycle and tropical sea surface temperatures. J. Climate, 17, 2213-2224.

Straub, K. H., and G. N. Kiladis, 2002: Observations of a convectively coupled Kelvin wave in the eastern Pacific ITCZ. $J$. Atmos. Sci., 59, 30-53.

__, and —_, 2003a: Extratropical forcing of convectively coupled Kelvin waves during austral winter. J. Atmos. Sci., 60, 526-543.

$\longrightarrow$, and — 2003b: Interactions between the boreal summer intraseasonal oscillations and higher-frequency tropical wave activity. Mon. Wea. Rev., 131, 945-960.

Takayabu, Y. N., and T. Nitta, 1993: 3-5 day-period disturbances coupled with convection over the tropical Pacific Ocean. J. Meteor. Soc. Japan, 71, 221-246.

Trenberth, K. E., 1984: Signal versus noise in the Southern Oscillation. Mon. Wea. Rev., 112, 326-332.

von Storch, H., and F. W. Zwiers, 1999: Statistical Analysis in Climate Research. Cambridge University Press, 484 pp.

Wang, B., 1988: Dynamics of tropical low-frequency waves: An analysis of the moist Kelvin wave. J. Atmos. Sci., 45, 20512065.

- 2005: Theory. Intraseasonal Variability in the AtmosphereOcean Climate System, Springer-Verlag, 307-360.

— , and H. Rui, 1990a: Dynamics of the coupled moist KelvinRossby wave on an equatorial $\beta$-plane. J. Atmos. Sci., 47, 397-413.

$\longrightarrow$, and $-1990 \mathrm{~b}$ : Synoptic climatology of transient tropical intraseasonal convection anomalies: 1975-1985. Meteor. Atmos. Phys., 44, 43-61.

— dynamics in the development of a tropical intraseasonal system. J. Atmos. Sci., 51, 1386-1400.

—_, and X. Xie, 1996: Low-frequency equatorial waves in vertically sheared zonal flow. Part I: Stable waves. J. Atmos. Sci., 53, 449-467.

Wheeler, M., and G. N. Kiladis, 1999: Convectively coupled equatorial waves: Analysis of clouds and temperature in the wavenumber-frequency domain. J. Atmos. Sci., 56, 374-399.

, and H. H. Hendon, 2004: An all-season real-time multivariate MJO index: Development of an index for monitoring and prediction. Mon. Wea. Rev., 132, 1917-1932.

, G. N. Kiladis, and P. J. Webster, 2000: Large-scale dynamical fields associated with convectively coupled equatorial waves. J. Atmos. Sci., 57, 613-640.

Xie, S.-P., and A. Kubokawa, 1990: On the wave-CISK in the presence of a frictional boundary layer. J. Meteor. Soc. Japan, 68, 651-657.

Yamagata, T., and Y. Hayashi, 1984: A simple diagnostic model for the 30-50 day oscillation in the tropics. J. Meteor. Soc. Japan, 62, 709-717.

Yanai, M., and M. Murakami, 1970: Spectrum analysis of symmetric and antisymmetric equatorial waves. J. Meteor. Soc. Japan, 48, 331-347.

- B. Chen, and W.-W. Tung, 2000: The Madden-Julian oscillation observed during the TOGA COARE IOP: Global view. J. Atmos. Sci., 57, 2374-2396.

Yasunari, T., 1979: Cloudiness fluctuations associated with the Northern Hemisphere summer monsoon. J. Meteor. Soc. Japan, 57, 227-242.

_ 1980: A quasi-stationary appearance of 30 to 40 day period in the cloudiness fluctuations during the summer monsoon over India. J. Meteor. Soc. Japan, 58, 225-229.

_ 1981: Structure of an Indian summer monsoon system with around 40-day period. J. Meteor. Soc. Japan, 59, 336-354.

Zhang, C., 1996: Atmospheric intraseasonal variability at the surface in the tropical western Pacific Ocean. J. Atmos. Sci., 53, 739-758.

—_, 2005: Madden-Julian Oscillation. Rev. Geophys., 43, RG2003, doi:10.1029/2004RG000158.

— nents of the intraseasonal oscillation in tropical convection. $J$. Atmos. Sci., 54, 741-752.

— , and M. Dong, 2004: Seasonality in the Madden-Julian oscillation. J. Climate, 17, 3169-3180. 